\title{
Sintagmas preposicionados nucleados por com como predicados de sentenças nominais na história do Português Brasileiro de Pernambuco ${ }^{1}$
}

\author{
Prepositional Phrases headed by com 'with' as predicates of nominal sentences in \\ the history of Brazilian Portuguese from Pernambuco
}

Maria Eduarda Genuino de Albertin* Marcelo Amorim Sibaldo**

\begin{abstract}
RESUMO: As sentenças nominais (ou copulares) ocorrem com os dois verbos cópulas do Português Brasileiro, ser e estar. Em relação à predicação nessas sentenças, o predicado seleciona seu sujeito. Assim, os sintagmas preposicionais predicados selecionam seu sujeito e, a depender da preposição núcleo, alteram o sentido do sintagma que os segue. Neste trabalho, procurou-se descrever os contextos sintáticos, pouco estudados em termos descritivos e teóricos, em que os predicados nucleados pela preposição com aparecem combinados a ser e estar. Neste estudo, lançando mão de corpora, verificamos uma maior ocorrência desse sintagma preposicional com o verbo estar. Assim, foram analisados, quantitativamente, através do mé-todo indutivo, documentos manuscritos e impressos correspondentes ao período do século XVIII ao XX, do estado de Pernambuco.
\end{abstract}

\begin{abstract}
Nominal sentences (or copular sentences) occur with both copulas in Brazilian Portuguese, i. e., ser and estar. In relation to predication in these sentences, predicate selects its subject. Thus, prepositional phrases predicate selects its subject and, depending on the head of the preposition, change the meaning of the phrase it follows. This paper aims to describe the syntactic contexts, under-researched in both descriptive and theoretical terms, in which the predicates headed by preposition com "with" appear combined to ser and estar. In order to do so, we use corpora and we verify a large occurrence of this prepositional phrase with the verbo estar. Therefore, we analyze quantitatively by inductive method, documents - manuscripts and printed ones - from the Century XVIII to Century XX from the state of Pernambuco.
\end{abstract}

\footnotetext{
* Graduanda em Letras: Português. Departamento de Letras/UFPE. eduarda.albertinn@gmail.com

** Doutor em Linguística. Professor do PPGL-UFPE e do Departamento de Letras/UFPE. sibaldo@gmail.com

${ }^{1}$ Gostaríamos de agradecer as observações e sugestões de dois pareceristas anônimos que fizeram a qualidade do texto melhorar enormemente. Os erros remanescentes são de inteira responsabilidade dos autores.
} 
PALAVRAS-CHAVE: Português Brasileiro. Sentenças Copulares. Sintagmas Preposicionais.
KEYWORDS: Brazilian Portuguese. Copular Sentences. Prepositional Phrases.

\section{Introdução}

O Português Brasileiro (doravante PB), como se sabe, possui dois verbos copulares: ser (originado do latim, sēdere, "estar sentado") e estar (do latim, stare, "estar de pé"). Comumente, o verbo cópula ser parece denotar uma propriedade do tipo individual level; já o verbo estar, por sua vez, denotaria uma propriedade do tipo stage level (sobre as propriedades stage/individual, ver CARLSON, 1977). Desse modo, o primeiro, de maneira geral, é usado para se referir a um atributo inerente ao sujeito, como em (1), enquanto o segundo, a um atributo temporário ou transitório, como em (2):

(1) A Maria é/ *está americana.

[Predicado individual level]

(2) A Maria está/ *é grávida. [Predicado stage level]

Dessa forma, os predicados adjetivais que se combinariam a cada um desses verbos cópulas - cf. (1) e (2) - seguiriam essas características: os predicados do tipo individual level, conforme Molina (2008, p. 2), não manifestariam mudança quanto a sua atribuição, não limitariam temporalmente o constituinte na posição gramatical de sujeito e atribuiriam a este propriedades estáveis. No que diz respeito aos predicados de natureza stage level, por determinarem uma função de maneira transitória, implicariam mudanças e seriam limitados espacial e temporalmente.

Entretanto, sob circunstâncias específicas, alguns sintagmas adjetivais podem ser combinados tanto a ser quanto a estar. Como se observa em (3), há uma concordância de gênero e número entre o sujeito e o sintagma adjetival predicado:

(3) a. A Maria élestá bonita.

b. As meninas são/estão bonitas.

c. O Carlos élestá feio.

d. Os meninos são/estão feios. 
As relações de concordância estabelecidas em (3) parecem ser uma evidência de que não são os verbos que selecionam (predicam sobre) o sujeito, mas sim o predicado (chamado de predicativo pela gramática tradicional) ${ }^{1}$. Assim, os sintagmas adjetivais [AP bonita/s] e [AP feio/s] seriam predicadores de um lugar e seriam saturados a partir da relação com o Sintagma Nominal (NP, do inglês Noun Phrase) sujeito. Os verbos cópulas, portanto, não exibiriam características de predicadores.

Com relação aos sintagmas preposicionais ( $\mathrm{PP}$, do inglês Prepositional Phrase) predicados, é importante ressaltar que a preposição núcleo, juntamente com o seu objeto e o sujeito de uma determinada sentença copular, definiria o "sentido" daquele PP predicado, como em (4), abaixo:

(4) a. O João estál *é [pp em São Paulo].

b. A caixa él *está [pp de papelão].

c. A Maria estál *é [pp com o Pedro].

d. O carro él *está [pp do Paulo].

Como vemos acima, e veremos adiante, os PPs predicados fazem restrição de seleção da cópula e, ainda, delimitam o sentido da sentença copular. Portanto, as

${ }^{1}$ Cumpre ressaltarmos que a relação de concordância é apenas uma das evidências de predicação, pois existem relações de predicação evidentes em que não podemos observar concordância morfologicamente visível, como em (i), em que o verbo transitivo comprar claramente seleciona semanticamente seu objeto [os livros do Chomsky], mas não concorda com este. Mesmo em sentenças copulativas, como as que selecionam PP predicados que examinaremos aqui, não podemos observar relação de concordância entre o sujeito e o seu predicado, como em (iib), por exemplo. Entretanto, semanticamente sabemos que as sentenças (iic) e (iid) - em comparação com as sentenças (iia) e (iib) são mal formadas, porque o predicado impõe restrições semânticas ao sujeito das copulativas. Em outras palavras: é o predicado que seleciona semanticamente (predica sobre) o sujeito. Assim, como será visto na próxima seção, assumiremos durante todo este artigo que o PP nucleado pela preposição com predica sobre seu sujeito dentro de projeção que chamaremos de Small Clause, exatamente como faz a literatura (cf. MORO, 1997; DUARTE, 2003; entre muitos outros).

(i) Eu comprei os livros do Chomsky.

(ii) a. A Maria é loira.

b. O livro está com capa dura.

c. *A pedra é loira.

d. *O vento está com capa dura. 
preposições (em conjunto com a semântica do NP sujeito e predicado) auxiliam no desencadeamento das ideias de contraposição (4a), de matéria (4b), de companhia (4c) e de posse (4d). É interessante pontuar que poucos são os trabalhos que desenvolvem uma análise sobre esses tipos de estruturas com PPs predicados. Por isso, o escasso estudo dessas sentenças na literatura linguística talvez faça com que elas sejam pouco entendidas, principalmente se formos levar em consideração estudos diacrônicos feitos no estado de Pernambuco.

Assim, objetivamos descrever as sentenças copulares cujo predicado é um PP nucleado por com, buscando compreender a semântica dessas estruturas e as restrições de seleção das cópulas ser e estar na história do PB escrito em Pernambuco. Para isso, usaremos como corpus documentos manuscritos e impressos dos séculos XVIII ao XX, do projeto Para a História do Português Brasileiro $(P H P B),{ }^{2}$ da equipe regional de Pernambuco, buscando exaurir todas as ocorrências de todas as sentenças copulares com predicados PPs nesses documentos. Dessa forma, a metodologia laboviana do uso de dados foi necessária. Para a explicação da derivação das sentenças copulares, cujo predicado é um PP nucleado por com, usamos a Gramática Gerativa, no seu modelo de Princípios \& Parâmetros (CHOMSKY, 1986).

Por isso, apesar de levarmos em consideração a quantificação dessas sentenças, por se tratar de um fenômeno muito específico e pouco usual, tanto na língua falada quanto na escrita, a contribuição deste artigo se dá na análise de corpora ainda não descritos com esse fenômeno e na discussão teórica que pode ser feita fundamentada nesses dados, pois, como se verá, apesar do árduo trabalho de seleção de dados, poucos foram os encontrados nos documentos da pesquisa. Entretanto, como sabemos, fazer Linguística Histórica é "a arte de fazer o melhor uso de maus dados" (LABOV,

2 Os corpora do projeto PHPB estão reunidos e podem ser acessados no site: https://sites.google.com/site/corporaphpb/. 
1994, p. 11) e, considerando essa afirmação, traremos uma discussão sobre esses dados do PHPB, as quais evidenciam nosso fenômeno.

Buscando descrever os contextos sintáticos e as implicações semânticas em que os PPs encabeçados por com em sentenças copulares ocorrem no PB em Pernambuco, o presente artigo está dividido da seguinte forma: na seção 2, faremos uma discussão sobre sentenças copulares e seus tipos de predicado, incluindo os PPs; na seção 3, explicitaremos os dados e sua seleção nos corpora do PHPB; na seção 4, apresentaremos os resultados encontrados nos documentos e discutiremos como os PPs predicados nucleados por com podem ser explicados na história do português; por fim, faremos uma retomada dos principais achados deste artigo.

\section{Sobre sentenças copulares e PPs predicados}

Como vimos em (3), é possível perceber que no PB (assim como no espanhol), por exemplo, alguns sintagmas adjetivais (AP, do inglês, Adjective Phrase) podem ser combinados aos dois verbos copulares ser e estar, não obstante a afirmação anterior das distinções entre predicados temporários e permanentes. Porém, como vimos em (1), nem sempre essa possibilidade está disponível.

Para que possamos trocar as cópulas ser e estar no PB, entretanto, há pelo menos uma opção, que é quando ancoramos temporalmente o predicado ao inserir um elemento sintático que indique temporalidade, como em (5) abaixo:

(5) a. A Joana é inteligente.

b. *A Joana está inteligente.

c. Hoje a Joana está inteligente.

O fenômeno apresentado em (5c) é conhecido na literatura como coerção (coercion, cf. MOLINA, 2008, p. 11), pois o contexto sintático muda, de modo que um predicado adjetival, antes combinado a ser, passa a funcionar também com estar. 
Além disso, é perceptível que os verbos copulares não impõem restrições semânticas à expressão que gramaticalmente exerce o papel de sujeito, ou seja, não limita seus traços, que podem ser [ \pm abst], $[ \pm$ hum] e/ou [ \pm anim]; antes, o predicativo do sujeito é quem predica sobre o sintagma nominal (NP, do inglês, Nominal Phrase) sujeito, como podemos ver em (6):

(6) a. A fome é desumana./ A beleza está feia.

b. A Maria é bonita./ O Pedro está cansado.

c. O cachorro é alemão./ A gata está sentada.
[Sujeito abstrato] [Sujeito humano] [Sujeito animado]

Devido a essa relação direta do predicado (predicativo do sujeito para a gramática tradicional) com o NP sujeito, Duarte (2003) analisa as sentenças copulativas como contendo um “domínio de predicação não frásico" e, portanto, sendo Small Clauses (SC), as quais, de modo geral, exibem uma estrutura em que "[...] o predicativo do sujeito é o predicado e o constituinte com a relação gramatical de sujeito o sujeito que o satura." (DUARTE, 2003, p. 540). Assim, uma construção como em (7a) possuiria uma configuração como em (7b):

(7) a. O João é curioso.

b.

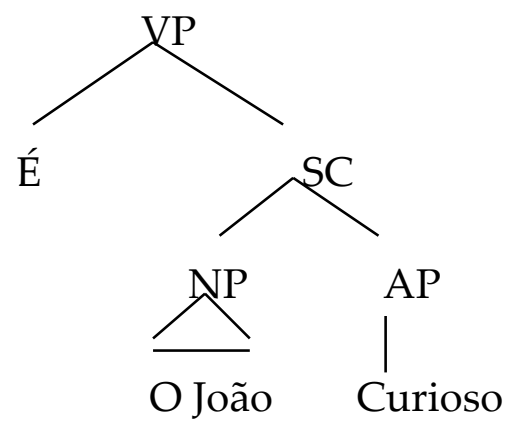

Na configuração da sentença exposta acima, temos uma relação de predicação entre o AP, na função de predicado, e o NP, como sujeito da Small Clause (SC) e 
argumento do AP. De acordo com Duarte (2003), a Small Clause é o argumento interno do verbo cópula e o AP mostra-se predicador sobre o NP.

As sentenças copulares podem ocorrer, também, com outro tipo de predicado: o PP. Quando combinados a um verbo cópula, os PPs podem alterar o sentido das sentenças. Esse fenômeno ocorre porque as preposições são predicadoras nesse tipo de construção, i.e., a depender da preposição núcleo do PP, a estrutura copular pode mudar de significado, como em (8 a-d):

(8) a. O menino está [pp em São Paulo]

[Locativo]

b. O menino está [pp com sua mãe].

[Companhia]

c. João é [pp de Sergipe].

[Origem]

d. O presente é [pr para Joana].

[Beneficiário]

Pode-se afirmar, então, que as preposições não são "vazias" de sentido, principalmente em sentenças copulares, uma vez que, para determinado significado, é preciso haver alteração na preposição núcleo. Por isso, as preposições podem ser atribuidoras de papel temático, o qual, como explana Berg, consiste em ser "[...] uma função de caráter derivado da relação específica que se estabelece entre o argumento e o predicador" (BERG, 2005, p. 31). Como vimos em (8 a-d), os NPs contidos nos PPs assumem um valor semântico diferente de acordo com a preposição que nucleia o PP.

Com efeito, podemos pensar em preposições de sentidos fracos e fortes, consonante Berg (2005). Isto implica conceber certas preposições como mais suscetíveis a diversos sentidos (como em, de, a, com, para, por), o que as tornaria fracas semanticamente; por outro lado, há preposições que evocam um (ou poucos) significado(s) por si sós, já que sua significação é mais demarcada (cf. 9). No primeiro caso, para conhecer seu sentido, é preciso que se saiba o ambiente sentencial no qual a preposição está inserida, dado que essas preposições possuem uma ampla gama de significados (10 a-b). 
(9) Ela está [pr sem o celular].

(10) a. O Mário é [pp de Maceió] b. O livro é [pr de Maria].
[Ausência]

[Origem]

[Posse]

É válido salientar, ainda, que algumas preposições passam pelo processo de gramaticalização, que, de acordo com Ilari et al. (2015), configura-se como o procedimento de transformação pelo qual um item lexical passa para se transformar num morfema. As preposições que se encontram, atualmente, mais gramaticalizadas no PB têm maior facilidade de introduzir argumentos verbais ou de se amalgamar a outros itens de uma sentença. A exemplo disso, temos a preposição com - que representa o núcleo PP foco deste artigo: ao longo do tempo, com (do latim, cum) se adjungiu ao pronome migo (do latim, mēcum) e atua como adjunto ou como predicativo do sujeito (11); vemos, também, a preposição $a$, que aparece frequentemente como introdutora de argumento (12).

\section{(11) A Maria está comigo. \\ (12) A menina foi à escola.}

Em se tratando da preposição com, esta ainda carrega as noções de companhia (ou comitativa) e de modo trazidas do latim por sua antecessora cum. Pode-se observar que houve uma mudança na forma da preposição cum, ao ser gramaticalizada do latim para o português (POGGIO, 2002); tal transformação culminou em com, que preservou as significações da preposição anterior. No tocante ao aspecto comitativo, nele há uma ideia de concomitância, ou seja, a presença de objetos e/ou de indivíduos ocorre paralelamente numa sentença; o sentido de modo, por sua vez, remete a como a ação se desenrolou. Esses dois casos são prototípicos de com. ${ }^{3}$

\footnotetext{
${ }^{3}$ Entretanto, podemos notar, no PB, ocorrências em que, segundo Ilari et al (2015), é necessário ampliar os sentidos comitativo e modal. Remetemos o leitor ao referido trabalho para verificar essa ampliação.
} 
No que concerne ao papel temático de modo (13a), este se mescla comumente a outras noções semânticas, como a de instrumento (13b). Contudo, é admissível que esse conceito seja comportado dentro da classificação modal, pois também diz respeito a como a situação transcorreu. Ademais, uma das possibilidades de extensão da ideia comitativa - e que se manifesta constantemente no PB - é a reinterpretação da relação parte-todo: "[...] a possibilidade de tratar as propriedades de um objeto como suas partes." (ILARI et al, 2015, p. 263). Assim, surge a concepção de que os objetos “contêm" seus atributos em si (14 a-b) - que pode, também, ser percebida como posse/pertencimento a um grupo -, com base na ideia anterior de presença simultânea numa ação.

(13) a. Ele a abraçou com alegria.

(Modo)

b. A menina escreveu com o lápis.

(Instrumento)

(14) a. A Maria quer o carro com duas portas.

b. A mulher tinha uma caneta com duas cores.

Por conseguinte, Ilari et al. (2015) afirmam ser provável que esses usos de com revelem a natureza atributiva que a preposição possui. Em razão disso, é possível relacionar a essas ocorrências o aparecimento de com como núcleo de PPs em sentenças copulares, porquanto uma das características que essas construções exibem é a de atribuir propriedades ao constituinte com relação de sujeito. Nessa combinação, é comum, no PB, que a preposição com seja selecionada pelo verbo cópula estar (cf. (15)) - em contrapartida a um PB mais arcaico, em que era frequente a presença de com numa sentença com ser (cf. (16)) -, dada a transitoriedade que o estar expressa.

(15) a. O João está com dor de cabeça.

[Português Brasileiro]

b. O Paulo está com dinheiro.

(16) ... e que en outro dia seeriam com ele.

[Português arcaico]

(MATTOS E SILVA, 2006, p. 151, ex. (6)) 
Dessa forma, podemos admitir que, possivelmente, os PPs nucleados por com apareçam mais facilmente em estruturas com a cópula estar devido à natureza “atributiva descritiva transitória" (MATTOS E SILVA, 1997) que a preposição com pode expressar.

\section{Sobre os dados}

Para a elaboração desta pesquisa, utilizamo-nos de uma abordagem quantitativa e do método indutivo para a análise dos corpora. Estes consistiram em 19 documentos impressos e 11 manuscritos, pertencentes ao estado de Pernambuco, disponíveis no banco de dados on-line do Projeto para a História do Português Brasileiro (PHPB) (disponível em: https://sites.google.com/site/corporaphpb/), da equipe regional do mesmo estado. Os documentos impressos correspondem ao período do século XIX ao XX e são divididos nos gêneros cartas de leitores, cartas de redatores e anúncios; enquanto os manuscritos são referentes aos séculos XVIII, XIX e XX e abarcam os gêneros cartas particulares e cartas oficiais. No total, foram coletados seis documentos de cartas de leitores, totalizando 113 cartas, variando de 11 a 38 páginas; oito documentos de cartas de redatores, variando de cinco a 121 páginas, sendo as cartas um total de 145; e cinco documentos de anúncios, que variaram de dez a 156 páginas e que contiveram 393 anúncios (cf. Tabela 1).

Com relação aos manuscritos, as cartas particulares (36) correspondiam a quatro documentos, que continham de duas a 36 páginas; as cartas oficiais (101), por sua vez, dividiram-se em sete documentos, que variavam de duas a 38 páginas (cf. Tabela 2). Dessa documentação extraíram-se todas as sentenças copulares cujos predicados fossem PPs; em seguida, os poucos dados relacionados às estruturas copulares com PPs nucleados por com foram selecionados para compor as discussões que serão feitas nesta pesquisa. 
Tabela 1 - Documentos impressos do século XIX ao XX.

\section{Cartas de \\ Cartas de \\ Anúncios \\ Total}

Leitores

Redatores

\begin{tabular}{l|c|c|c|c|}
$\begin{array}{l}\text { Quantidade de } \\
\text { documentos }\end{array}$ & 6 & 8 & 5 & 19 \\
\hline $\begin{array}{l}\text { Quantidade de } \\
\text { cartas/anúncios }\end{array}$ & 113 & 145 & 393 & 651 \\
\hline $\begin{array}{l}\text { Número de } \\
\text { páginas }\end{array}$ & $11-38$ & $5-121$ & $10-156$ & \\
\hline
\end{tabular}

Tabela 2 - Documentos manuscritos do século XVIII ao XX.

\begin{tabular}{|c|c|c|c|}
\hline & $\begin{array}{c}\text { Cartas } \\
\text { Particulares }\end{array}$ & $\begin{array}{l}\text { Cartas } \\
\text { Oficiais }\end{array}$ & Total \\
\hline $\begin{array}{l}\text { Quantidade de } \\
\text { documentos }\end{array}$ & 4 & 7 & 11 \\
\hline $\begin{array}{l}\text { Quantidade de } \\
\text { cartas/anúncios }\end{array}$ & 36 & 101 & 137 \\
\hline $\begin{array}{l}\text { Número de } \\
\text { páginas }\end{array}$ & $2-36$ & $2-38$ & \\
\hline
\end{tabular}

Como se pode verificar acima, a configuração dos documentos analisados para este artigo constitui uma grande diferença de gêneros. Entretanto, como não há diferenças em relação à estigmatização/não estigmatização social desse fenômeno no português, acreditamos que abarcar todos os gêneros e não os controlar não fará diferença quanto aos resultados.

Outro ponto importante a ser ressaltado nas tabelas sobre os corpora utilizados neste artigo e que já foi mencionado anteriormente é o fato de que todos os documentos que aparecem nas tabelas 1 e 2 acima são disponibilizados para o público do projeto PHPB. Dessa forma, o objetivo em relação aos dados neste artigo foi o de exauri-los completamente do PHPB, independentemente dos resultados. A exaustão será importante, inclusive, para trabalhos futuros, quando se poderá, separadamente, 
compará-los com outros corpora do português (inclusive de outros estágios dessa língua).

\section{Sobre os PPs predicados na história do português pernambucano: os resultados}

Na análise dos documentos - cartas de leitores (CL), cartas de redatores (CR), anúncios $(\mathrm{AN})$, cartas particulares $(\mathrm{CP})$ e cartas oficiais $(\mathrm{CO})-$, pudemos perceber poucas aparições de sentenças copulares com PPs como predicado. No entanto, os dados puderam demonstrar quais os níveis de ocorrências das preposições núcleos (em, de, a, com, para, por, contra, e sem) e a qual dos verbos (ser e estar) elas mais foram combinadas nas estruturas copulares (cf. Tabela 3).

Tabela 3 - Dados gerais sobre os PPs como predicados de sentenças copulares.

\begin{tabular}{|c|c|c|c|c|c|c|c|c|c|}
\hline Cópula & $D e$ & $E m$ & $A$ & Por & Para & Com & Contra & Sem & $\begin{array}{c}\text { Total } \\
(\%)\end{array}$ \\
\hline Ser & 9 & 62 & - & 6 & 6 & - & 2 & 1 & $\begin{array}{c}86 \\
(49 \%)\end{array}$ \\
\hline Estar & 60 & 8 & 15 & 4 & 2 & 2 & - & - & $\begin{array}{c}91 \\
(51 \%)\end{array}$ \\
\hline $\begin{array}{c}\text { Total } \\
(\%)\end{array}$ & $\begin{array}{c}70 \\
(39 \%)\end{array}$ & $\begin{array}{c}69 \\
(39 \%)\end{array}$ & $\begin{array}{c}15 \\
(8 \%)\end{array}$ & $\begin{array}{c}10 \\
(6 \%)\end{array}$ & $\begin{array}{c}8 \\
(5 \%)\end{array}$ & $\begin{array}{c}2 \\
(1 \%)\end{array}$ & $\begin{array}{c}2 \\
(1 \%)\end{array}$ & $\begin{array}{c}1 \\
(1 \%)\end{array}$ & $\begin{array}{c}177 \\
(100 \%)\end{array}$ \\
\hline
\end{tabular}

Fonte: elaborada pelos autores.

É notável, logo de início, a predominância das preposições de e em em detrimento das outras. Esse fenômeno dar-se-ia em razão da significação fraca que essas preposições possuem, o que, visivelmente, facilita seus usos em diversos contextos sintáticos, principalmente de, em e $a$. Com relação às outras preposições (com, contra e sem), estas ocorrem num percentual menor (1\%), em sentenças com sentidos mais específicos, uma vez que ambas têm significados bem demarcados: em com, temos a ideia de companhia; em contra, há uma ideia palpável de oposição; enquanto em sem, tem-se ausência. Nas três construções em que as duas últimas preposições 
apareceram, as sentenças denotaram as significações acima; no concernente às demais preposições, estas variaram de significado e atribuíram papéis temáticos diferentes.

No que diz respeito à preposição enfocada neste trabalho, cuja aparição representa $1 \%$ dos dados gerais (cf. Tabela 4), com foi encontrada em duas sentenças ao longo dos documentos: uma nas $\mathrm{CR}$ e uma nas $\mathrm{CP}$. Mesmo sabendo que essa questão não parece ser relevante para o aparecimento do fenômeno em estudo, é importante salientar que as CRs têm um nível maior de formalidade; já as CP, por serem endereçadas a amigos ou a familiares, não exigem uma formalidade maior.

Tabela 4 - Dados sobre com como núcleo em PPs predicados de sentenças copulares.

\begin{tabular}{|c|c|c|c|}
\hline Cópula & Comitativo & Modo & $\begin{array}{c}\text { Total } \\
(\%)\end{array}$ \\
\hline Ser & - & - & - \\
\hline Estar & 2 & - & 2 \\
\hline Total & 2 & - & $100 \%$ \\
\hline
\end{tabular}

Fonte: elaborada pelos autores.

Na tabela acima, verificamos que $100 \%$ dos PPs predicados encabeçados pela preposição com ocorreram numa sentença copular com o verbo estar. Podemos perceber, então, o reforçamento da ideia de que, por ser uma preposição atributiva, e esses atributos serem do tipo descritivo transitório, com, majoritariamente, seria selecionada por estar, como em (17), confirmando, portanto, nossa hipótese inicial. Essas ocorrências revelam a modernidade dos documentos aqui analisados, tendo em vista que ser já foi um verbo cópula mais utilizado do que estar, como vimos em (16).

(17) “Mamãe está com ele." (Companhia) 
Em (17) - retirado das $\mathrm{CP}$-, tem-se uma construção ainda mais prototípica do sentido comitativo da preposição com. Os NPs "Mamãe" e "ele" se relacionam de modo paralelo, dado que ambos estão simultaneamente na companhia um do outro. Além disso, poderíamos afirmar que o papel temático acima ainda está envolto por uma percepção de transitoriedade, porquanto a compreensão de companhia remete a uma relação momentânea entre os dois constituintes da sentença - o que, reiterando, justificaria o uso do estar.

Por fim, vejamos o que ocorre em (18), o segundo e último dado de nosso corpus:

(18) “[...] como meio de provar I que a opinião do paiz está, desde muiI tos annos, com os Nabucos, Zacarias, I Saraiva e muitos outros distinctos par- |lamentares." (Posse)

Em (18) - terceiro dado de um PP predicado nucleado por com, encontrado nas CE -, há uma relação interessante de concomitância: o NP “opinião do paiz" aparece como uma propriedade dos "Nabucos, Zacarias, Saraiva e muitos outros distinctos parlamentares". Assim, esse fenômeno nos conduz à possibilidade de admitir o papel temático da sentença como "posse", dado que o NP predicado aparece como detentor, possuidor do NP com relação de sujeito.

Dessa forma, foi possível notar nos documentos, como dito anteriormente, as ocorrências da preposição com unicamente combinada ao verbo estar, enquanto sua seleção por ser foi nula. Assumimos, então, que em virtude do declínio do ser como verbo cópula mais recorrente (MATOS E SILVA, 1997), sua adjunção a predicados PPs nucleados por com teria, também, decaído em sentenças transitórias. Como vemos na tabela abaixo, no século XIII, mesmo nas estruturas transitórias, o verbo ser ainda 
detinha a grande maioria dos usos, o que, como sabemos, foi se perdendo ao longo da história do português. ${ }^{4}$

Tabela 5 - Atributos transitórios com as cópulas ser e estar no português arcaico (Séc. XIII).

\begin{tabular}{c|c|c|c|c|c|c|} 
Atributos & \multicolumn{2}{c}{ ADT } & \multicolumn{2}{c}{ ALT } & \multicolumn{2}{c}{ ALNT } \\
\cline { 2 - 7 } transitórios & $\mathrm{N}$ & $\%$ & $\mathrm{~N}$ & $\%$ & $\mathrm{~N}$ & $\%$ \\
\hline Ser & 121 & $93 \%$ & 43 & $81 \%$ & 22 & $69 \%$ \\
\hline Estar & 10 & $7 \%$ & 10 & $19 \%$ & 10 & $31 \%$ \\
\hline Total & 131 & $100 \%$ & 53 & $100 \%$ & 32 & $100 \%$ \\
& & \multicolumn{2}{c}{ Fonte: Mattos e Silva (1997, p. 264). } & & \\
\end{tabular}

Nos estágios seguintes do português, a literatura (ver, sobretudo, MATTOS E SILVA, 2006) observa que ser passa a ocorrer mais em estruturas que indicam inerência, e estar, por sua vez, assume as que designam atributos passageiros.

É substancial frisar, ainda, a ausência de com em sentenças copulares expressando modo. Apesar dessa inexistência, constatou-se que era recorrente a aparição da preposição como adjunto com valor de modo nos documentos analisados. No entanto, essas construções não fazem parte da investigação e dos objetivos desta pesquisa.

Alicerçados em nossos resultados e com base nas estruturas arbóreas apresentadas na seção 2, acima, podemos atribuir às sentenças que retiramos do nosso corpus a seguinte derivação:

\footnotetext{
4 As siglas significam, respectivamente: ADT: Atributiva Descritiva Transitória; ALT: Atributiva Locativa Transitória; e ALNT: Atributiva Locativa Nocional Transitória.
} 
(19) a. Mamãe está com ele.

b.

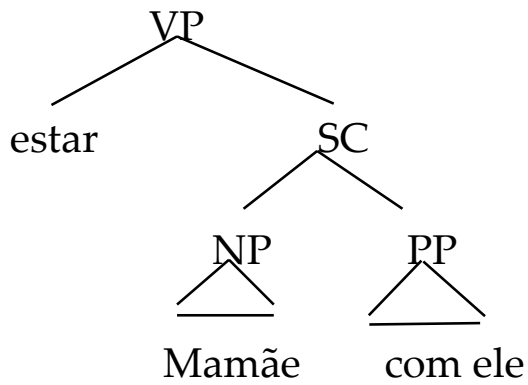

De acordo com (19), podemos observar que o PP [pp com ele] predica o NP sujeito [NP mamãe], formando a Small Clause. O verbo estar é adicionado à estrutura na função de núcleo de um sintagma verbal. ${ }^{5}$ Em seguida, é acrescentado o sintagma de flexão à estrutura (19b), desencadeando (20):

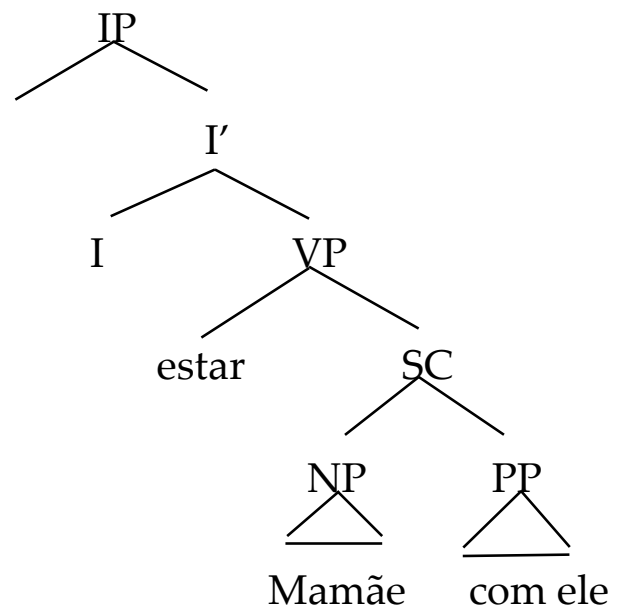

Os próximos passos derivacionais para deflagrar uma sentença copular do português são: o verbo estar, a fim de verificar os traços da flexão verbal de tempo,

\footnotetext{
${ }^{5}$ Observe que não fazemos distinção entre $v$ (verbo leve) e $\mathrm{V}$ (verbo lexical), uma vez que não é o propósito deste artigo fazer esse tipo de discussão e a representação em (20) está adequada para a discussão que aqui se quer mostrar. É importante mencionar, ainda, que estamos considerando a cópula estar como um verbo de alçamento, assim como a literatura faz com as cópulas de forma geral (STOWELL, 1978; MORO, 1997; RECH, 2011; entre muitos outros). Assim, esse tipo de verbo não seleciona semanticamente um sujeito (logo, a posição de sujeito [Spec, VP] não precisa ser projetada), mas seleciona, como seu complemento, uma Small Clause, cujo sujeito necessita checar seu Caso e, para isso, deve ser alçado para a posição [Spec, IP], em que tem seu Caso Nominativo checado.
} 
modo e aspecto, verbo esse alçado para o núcleo I, em que se flexiona para a forma $e^{e s t a ́}, 6$ deixando o vestígio (aqui representado por $t$, do inglês trace) ${ }^{7}$ no seu lugar de origem; e o NP "Mamãe", que, como não tem Caso Nominativo - e todo Sintagma Nominal deve ter Caso devido ao filtro do Caso (CHOMSKY, 1986) -, é alçado para a posição de especificador de IP, onde recebe Caso de I, deixando seu vestígio na posição de sujeito da SC. O que foi dito neste parágrafo pode ser visto em (21), abaixo:

tv

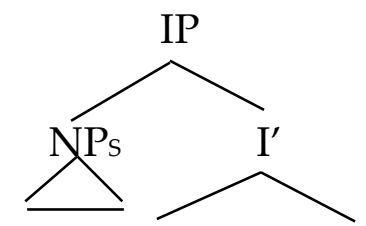

Mamãe I

está
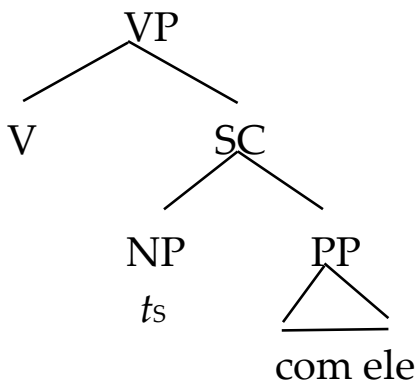

Como vimos com base em nossos dados, a árvore em (21) é suficiente para representar a derivação da sentença copular "Mamãe está com ele", retirado do nosso corpus. Entretanto, é importante destacar que somente estudos mais profundos e com uma maior quantidade de dados deverão nos dar pistas sobre o que aconteceu com a ampliação do domínio dos atributos transitórios pelo estar em detrimento de ser, como pode ser visto na Tabela 5, acima. Somente com uma maior quantidade de dados e de contextos é que poderemos elucidar quais traços sintáticos e semânticos entraram em

\footnotetext{
${ }^{6}$ Veja, entretanto, Gallego e Uriagereka (2016) que propõem uma análise mais refinada para o estar (em detrimento do ser), baseados na ideia de incorporação de preposição de Benveniste (1966). Não iremos nos ater a essa proposta, visto ser suficiente a proposta em (21). Remetemos o leitor ao texto mencionado e às referências lá citadas para maiores detalhes.

${ }^{7}$ Deixamos um índice subscrito $\mathrm{S}$ em $t$ para indicar o vestígio do sujeito e $\mathrm{V}$ para indicar o vestígio do verbo.
} 
jogo para que essa "invasão" de territórios do estar sobre o ser se desse no português. Dessa forma, nossa pesquisa continua.

\section{Considerações finais}

Com os dados obtidos na análise dos documentos, pudemos perceber, não obstante a pouca ocorrência, que a preposição com mantém seu sentido comitativo, oriundo do latim, nas sentenças copulares. Contudo esse valor semântico pode ser ampliado, a fim de dar conta de outros papéis temáticos que com pode atribuir ao predicado PP, quando combinado a verbos cópulas, especialmente ao estar. Por isso, podemos admitir com como atribuidora de características descritivas transitórias, uma vez que, em 100 \% das aparições em construções copulares, a preposição foi selecionada pelo verbo estar, remetendo, portanto, a características transitórias.

Além disso, esta pesquisa ressalta a substancialidade de trabalhos que se debrucem sobre as estruturas cópulas e, também, sobre os PPs, dado que essas construções exibem fenômenos muito pouco estudados. É perceptível, ainda, a importância de que haja explicações linguísticas para questões sintáticas que se manifestam ao longo da história do PB, com a finalidade de desenvolver estudos teóricos que abarquem esses fenômenos, como é o caso do ser e do estar e de seus possíveis predicados.

\section{Referências}

BENVENISTE, É. Être et avoir dans leur function linguistique. In: BENVENISTE, É. Problèmes de linguistique générale. Paris: Gallimard, 1966. DOI https://doi.org/10.7202/500389ar

BERG, M. B. O Comportamento Semântico-Lexical das Preposições do Português do Brasil. Tese (Mestrado em Linguística), Universidade Federal de Minas Gerais, Belo Horizonte, 2005. DOI https://doi.org/10.14393/19834071.2016.36163 
CARLSON, G. Reference to Kinds in English. Tese de Doutorado. University of Massachusetts at Amherst, 1977.

CHOMSKY, N. Knowledge of Language: Its Nature, Origin and Use. Greenwood Publishing Group. New York: Praeger, 1986.

ILARI, R. et al. A Preposição. In: ILARI, R. (org.). Gramática do português culto falado no Brasil: volume IV: palavras de classe fechada. São Paulo: Contexto, 2015.

DUARTE, I. A família das construções inacusativas. In: MIRA MATEUS, M. H. et al. Gramática da Língua Portuguesa ( $5^{\mathrm{a}}$ edição, revista e aumentada). Lisboa (Editorial Caminho - Colecção Universitária / Série LINGUÍSTICA), 2003. p. 507-548.

GALLEGO, Á. J.; URIEGEREKA, J. Estar = Ser + X. Borealis - An International Journal of Hispanic Linguistics, v. 5, n. 1, p. 123-156, 2016.

LABOV, W. Principles of linguistic change: internal factors. Oxford: Blackwell, 1994.

MATTOS E SILVA, R. V. Observações sobre a variação no uso dos verbos ser, estar, haver, ter no galego-português ducentista. Estudos lingüísticos e literários, v. 19, p. 253-285, 1997.

MATTOS E SILVA, R. V. O Português Arcaico: Fonologia, Morfologia e Sintaxe. São Paulo: Contexto, 2006.

MOLINA, Silvia Gumiel. Sobre las diferencias entre ser y estar. El tipo de predicado y el tipo de sujeto. Redele: Revista Electrónica de Didáctica ELE, n. 13, jun. 2008.

MORO, A. The raising of predicates. Cambridge: CUP, 1997.

POGGIO, R. M. G. F. Aspectos da gramaticalização na história das preposições do latim ao português. Revista do GELNE, v. 4, n. 2, p. 1-7, 2002.

RECH, N. F. Verbos de reestruturação no Português Brasileiro. Revista do GEL, São Paulo, v. 8, n. 1, p. 165-182, 2011.

STOWELL, T. What Was There Before There Was There. Papers from the Fourteenth Regional Meeting of the Chicago Linguistic Society. Chicago: Chicago Linguistic Society. p. 458-471, 1978. 